\title{
O estado de exceção como um espaço vazio de direito
}

\section{The state of exception as a lawless space}

\section{Lucas Moraes Martins*}

\section{Resumo}

O presente artigo objetiva apresentar de forma concisa uma reflexão à seguinte pergunta: o que acontece com o direito no estado de exceção? A partir da obra de Giorgio Agamben, buscou-se explicar como a situação-limite do estado de exceção não parece ancorar-se no estado de necessidade, conforme ensina a tradição jurídico-política, isto é, não se reduz completamente a uma situação jurídica, mas surge em virtude do veredicto performativo de uma decisão. O que parece existir na situação excepcional é um limiar de indeterminação entre ius e factum, nómos e anomia, direito e vida, norma jurídica e violência, não havendo uma plenitude de poderes jurídicos, e sim um vazio jurídico, um espaço kenomatico. Justamente nesse campo de indeterminação podese decidir sobre o valor e o desvalor da vida, sem violar o direito. Entender urgentemente o funcionamento dessa situação-limite torna-se essencial para descortinar os espaços de exceção existentes dentro das atuais democracias.

Palavras-chave: Estado de exceção. Estado kenomatico. Direito. Democracia. Giorgio Agamben.

\section{Abstract}

This article presents a brief reflection to the question: what happens to the Law in the state of exception? From the work of Giorgio Agamben we sought to explain how the limit-figure of the state of exception does not seem to be anchored in a state of necessity, as taught by the legal and political tradition, or better, the

Doutor em Direito pela Universidade Federal de Minas Gerais. Professor da Universidade Fundação Mineira de Educação e Cultura. Belo Horizonte - Minas Gerais - Brasil. Email: lucasmoraesmartins@hotmail.com 
state of exception can not be completely reduced to a legal situation, but arises because of a performative verdict, by a decision. What appears to emerge in the exceptional situation is a threshold of indeterminacy between factum and ius, anomie and nomos, law and life, rule and violence, where there isn't a plenitude of legal powers, but a legal vacuum, a kenomatic space. Precisely in this field of indeterminacy one can decide on the value and worthlessness of life, without, however, violating the Law. Understanding urgently the mechanism of the state of exception becomes essential to uncover the spaces of exception existing within current democracies.

Keywords: State of exception. Kenomatic space. Law. Democracy. Giorgio Agamben.

\section{Introdução}

O estado de exceção, originalmente, é caracterizado pela suspensão temporário do ordenamento jurídico, um gesto pelo qual se alternariam momentos de normalidade e de excepcionalidade. Entretanto, quando modernamente se procurou dar uma localização visível permanente ao estado de exceção, o resultado foi o campo de concentração, um espaço absoluto de exceção que vigora como uma situação normal (AGAMBEN, 2010, p. 26). Ao se dar uma localização territorial ao estado de exceção (campo), criou-se um lugar onde os habitantes estavam continuamente expostos a uma violência que pode, a todo instante, decidir sobre o valor e o desvalor da vida. "Cheios de si próprio até ao bordo, o Völkerkörper alemão não podia viver a não ser evacuando continuamente a sua carne purulenta: talvez por isso um outro médico nazi chamara a Auschwitz anus mundi' (ESPOSITO, 2010, p. 204).

A partir da situação-limite do campo, um paradigma, cuja tarefa é constituir e tornar inteligível um conjunto problemático mais abrangente (AGAMBEN, 2008, p. 11), busca-se uma reflexão à seguinte pergunta: o que acontece com o direito, principalmente os fundamentais, no estado de exceção? A dificuldade da tradição jurídico-política em situar teoricamente o estado de exceção é a mesma que se encontra ao se 
pensar em um possível direito de resistência em relação às medidas excepcionais. A resistência, assim como a exceção, parece se situar em uma mesma fronteira ambígua e incerta, uma "interseção do jurídico e do político, do público e do privado, do subjetivo e do normativo" (FONTANA, 1999 , p. 16) ${ }^{1}$, ocupando uma posição que não é estritamente jurídica, nem simplesmente política. Falar, portanto, em um direito de exceção ou em um direito de resistência soa deveras duvidoso.

O formato da pesquisa do artigo ora apresentado, apesar de não exaurir-se na vertente jurídico-sociológica, aproxima-se desta, porquanto propõe compreender o fenômeno do estado de exceção em um ambiente mais amplo do que o dogmático fornecido pelos elementos internos do sistema jurídico. Se, em um primeiro momento, buscou-se entender a exceção no mundo medievo, foi apenas para demonstrar como o princípio fundamental da exceção medieval (necessitas legem non habet) ecoou na modernidade. Não se pretendeu, obviamente, comparar realidades históricas desconsiderando as respectivas peculiaridades, e sim lançar um olhar ao passado medieval para demonstrar a dificuldade teórica na qual se encontra a tradição moderna em relação à estrutura topológica do estado de exceção.

Entender o lócus impar do estado de exceção, lugar em que os conceitos de direito subjetivo e proteção jurídica perdem todo o sentido, não significa, tampouco, realizar um estudo historiográfico, mas uma tentativa de lançar luz nos espaços de exceção existentes dentro das atuais democracias. Sendo verdade que exista uma contiguidade essencial entre democracia e totalitarismo (AGAMBEN, 2010, p. 117118), norma e exceção, direito e violência, caberia, portanto, uma ampla revisão sem reservas do próprio papel do direito, questionamento que o presente artigo não pretende responder, mas o coloca, implicitamente, sob a forma de convite.

No original: "La résistance se situe en effet dans cette frange ambiguë et incertaine, borderline, qui est à l'intersection du juridique et du politique, du public et du privé, du subjectif e du normatif $[\ldots]^{\prime \prime}$. 


\section{0 problema do estado de necessidade}

O estado de exceção moderno, segundo a tradição jurídicopolítica, fundamenta-se na máxima latina necessitas legem non habet - a necessidade não tem lei (AGAMBEN, 2007, p. 40-41). Não à toa foi dito nos escritos políticos, no início do século XVII, que a necessidade emudece as leis, isto é, liberta-se das leis (FOUCAULT, 2008, p. 350351).

Todavia, antes da era moderna, esse brocardo foi utilizado na Idade Média para a elaboração de teorias sobre uma espécie de exceção (dispensatio), as quais fundamentariam o poder do rei de dispensar a lei em virtude de um caso particular. Refere-se, aqui, principalmente, às teorias de Jean de Salisbury e Tomás de Aquino, nos séculos XII e XIII, respectivamente (SAINT-BONNET, 2001, p. 123).

A estrutura teórica de Jean de Salisbury e Tomás de Aquino foi construída sobre uma ideia central, qual seja o imperativo de conservação da comunidade. Esse imperativo indicava uma lógica específica que permitiria a conservação do rei e do reino. Tal lógica foi denominada de ratio status Regis, regni ou rei publicae, que significava a arte ou a ciência de como ser o rei (SAINT-BONNET, 2001, p. 121).

Pode-se dizer que o imperativo de preservação do rei e do reino (ratio status Regis) englobava um mecanismo que articulava uma ratio communis utilitatis (ratio normal) e uma ratio necessitatis aut utilitatis (ratio excepcional), mesmo que de formas diferentes em Jean de Salisbury e Tomás de Aquino.

Abordando o poder real, Jean de Salisbury, ao comentar a fórmula Quod principi placuit legis habet vigorem, afirma que o rei, enquanto ministro da lei e da equidade, tinha a missão de oferecer uma vida sem danos aos súditos. Velando pela salus hominum, o rei não poderia querer, no sentido de deter uma vontade potencialmente arbitrária, pois estaria submetido a um princípio que o transcenderia: a ratio communis utilitatis, que, ao coincidir com a lei e a equidade, tornava-se o princípio 
diretor do poder real normal em prol do reino (SAINT-BONNET, 2001, p. 123).

Entretanto, mesmo que o rei, a princípio, não tivesse vontade pessoal arbitrária, por vezes a injustiça humana o obriga a tomar medidas para assegurar aos "justos" uma vida sem maiores danos. Essa ratio se funda na salus publica (SAINT-BONNET, 2001, p. 123), isto é, o rei poderia se valer de medidas necessárias para salvaguardar o reino e assegurar a todos (isto é, aos súditos "justos") uma vida sem danos. 0 benefício de todos, a "saúde" pública, justificaria essas medidas e, assim, o rei poderia, por exemplo, torturar os participantes de uma sedição, em virtude de uma ratio necessitatis aut utilitatis (SAINT-BONNET, 2001, p. 123).

$\mathrm{Na}$ verdade, o movimento realizado por Jean de Salisbury hipertrofia o poder normal da ratio communis utilitatis e acaba por englobar quase totalmente a ratio communis necessitatis aut utilitatis, invocada em situações particulares. Essas duas razões, normal e excepcional, entretanto, não se opõem como se fosse duas ordens distintas, mas tendem a se aproximar pela essência divina do poder real. A necessidade não poderia ser princípio de exceção como entendida modernamente, pois as duas razões coincidiriam na figura "soberana" do rei.

Em outros termos, segundo Jean de Salisbury, o tirano era o rei que praticava a tergiversação contra Deus e voltava as costas à lei divina. "Se o príncipe punir os rebeldes, não é tanto porque a comunidade está em perigo, mas porque o rei é a imagem de Deus e os insurgentes cometeram um sacrilégio" (SAINT-BONNET, 2001, p. 124)². O rei permanece rei e não tirano, mesmo em casos de necessidade, mesmo atuando por força da ratio necessitatis aut utilitatis.

Apenas com Tomás de Aquino - que retoma propriamente a máxima necessitas legem non habet - a ratio communis utilitatis (ratio

2 No original: "Si le Prince châtie les séditieux, c'est moins parce que la communauté est en danger que parce que lei roi est l'image de Dieu et que insurges commettent un sacrilège". 
normal) e a ratio communis necessitatis aut utilitatis (ratio excepcional) são claramente distinguidas, ocupando espaços delimitados (SAINTBONNET, 2001, p. 125). O aporte de Tomás de Aquino reside justamente na noção de que a comunidade política resulta de uma necessidade natural, fruto de uma lei natural. Seguindo uma linha não apenas teológica, mas também antropológica - o homem como animal político inserido em uma sociedade também política -, Tomás de Aquino pode afirmar que a coletividade deve tender à perfeição que é o bem comum (SAINT-BONNET, 2001, p. 118-124).

Por conseguinte, o rei bom era aquele que promovia o bem comum, agia retamente, recte agere, isto é, regere (SAINT-BONNET, 2001, p. 119). O rei injusto ou tirano não se encontrava mais naquele que diretamente tergiversava contra Deus, mas naquele que ignorava o bem comum. Entretanto, entre o rei bom e o tirano se intercalava a figura de um rei que deveria cumprir uma missão especial: preservar a existência da comunidade, embora cometesse ações injustas impelido pelas situações de necessidade que o obrigariam a atuar protegendo o bem comum, conforme ordena a lei natural. Entre o bom rei e o tirano, intercala-se um rei cuja missão especial a cumprir seria "preservar a comunidade e sua existência, podendo cometer ações injustas, porque estas são necessárias em virtude da lei natural" (SAINT-BONNET, 2001, p. 124$)^{3}$.

Em outros termos, a ratio normal (ratio communis utilitatis) reside no governo do rei, na condução dos homens ao bem comum, utilizando-se, para tanto, dos meios justos. Todavia, o rei, para preservar as condições de existência do bem comum, estaria obrigado a praticar ações injustas em virtude da necessidade: surge a esfera da ratio communis necessitatis. A ratio necessitatis aparece, assim, porque a lei natural do exercício do governo estaria subordinada à lei divina, a qual,

No original: "Entre le bon roi et le tyran, s'intercale un roi qui doit accomplir une mission spéciale, préserver la communauté dans son existence, fût-ce en commettant des actions injustes, parce que cela est nécessaire en vertu de la loi naturelle." 
em última instância, prescreveria que as condições do bem comum deveriam subsistir sob qualquer circunstância, porque a convivência em comunidade obedeceria aos desígnios divinos (SAINT-BONNET, 2001, p. 125).

As medidas tomadas em virtude da ratio necessitatis teriam, por conseguinte, duas justificativas, uma jurídica e outra política. A justificativa jurídica é devido à lei natural, que, inserida dentro do próprio projeto divino, autorizaria a tomada de medidas necessárias para preservar a comunidade e a política, porque caberia ao rei avaliar a oportunidade das medidas (SAINT-BONNET, 2001, p.125).

Em suma, para os propósitos deste artigo, pode-se condensar o pensamento de Jean de Salisbury e Tomás de Aquino sobre a exceção do seguinte modo: para o primeiro, a ratio necessitatis (excepcional) tende a se aproximar da ratio communis utilitatis (normal), porque o rei, utilizando-se de uma ou de outra, atuava sempre com justiça, desde que não tergiversasse contra Deus. Já para Tomás de Aquino, entre o rei justo, aquele que promovia o bem comum sob o império da ratio communis utilitatis, e o rei injusto, aquele que ignorava o bem comum, existiria um terceiro elemento. Entre o rei justo e o injusto (tirano), encontrava-se o rei que estaria obrigado a cometer ações injustas para salvaguardar as condições propícias para a realização do bem comum, valendo-se, portanto, da ratio necessitatis (excepcional).

Se Tomás de Aquino fundou duas esferas de legalidade, a normal e a excepcional, isso não implica que o mundo medievo tenha conhecido um verdadeiro estado de exceção ou mesmo um estado de necessidade. Segundo Agamben (2007, p. 41), firme na convicção da tradição democrático-revolucionária do estado de exceção, o medievo conheceu apenas teorias sobre uma espécie de exceção como dispensatio, isto é, uma formulação que implicava simplesmente o desaparecimento da vis obligandi da lei.

A exceção medieval conduzia apenas à dispensa (dispensatio), pela qual um caso particular escaparia à obrigação de obediência à lei, já que a necessidade não funcionava como fonte de lei ou mesmo forma 
a suspender a lei, no sentido próprio do termo. A teoria da exceção, ou mesmo da necessidade, em Tomás de Aquino, apenas fazia com que a lei perdesse a força de obrigação em um determinado caso concreto (AGAMBEN, 2007, p. 41). Um exemplo disso seria a ascensão ao episcopado de uma pessoa impedida de assumir tal ministério e que, entretanto, já foi consagrada bispo. "Aqui, paradoxalmente, a lei não se aplica porque o ato transgressivo já foi realizado e sua punição implicaria consequências negativas para a Igreja" (AGAMBEN, 2007, p. 42). O mundo medieval, portanto, com a teoria da exceção (dispensatio), simplesmente abria o próprio sistema jurídico a um fato externo, como se a transgressão tivesse sido legítima.

Se o medievo não conheceu um verdadeiro estado de exceção, se a necessidade não poderia ser um princípio de exceção ${ }^{4}$, pode-se ao menos afirmar que a exceção medieval, depois de Tomás de Aquino, revela uma aporia que, em um paralelismo interessante, encontra-se em sua forma integral no estado de exceção moderno.

Em períodos calmos, o rei deveria governar segundo uma ratio normal em favor do benefício comum, observando os limites atribuídos ao seu poder. Entretanto, diante da ameaça de um perigo, surgia uma distorção entre o imperativo de salvaguardar a comunidade política e os meios justos de que se dispunha para realizar esta tarefa. Essa lacuna era preenchida ao se invocar a ratio necessitatis. A necessidade apenas

4 Diferentemente de Agamben, Saint-Bonnet (2001, p.120; 134-135) entende que o mundo medievo conheceu um estado de exceção, ou melhor, que a necessidade era um princípio de exceção, ao menos depois de Tomás de Aquino. Todavia, para Agamben (2007, p.11-49), o homem medieval não poderia ter conhecido um estado de exceção, muito embora tenha teorizado sobre a exceção e a necessidade, principalmente por três motivos: a) o estado de exceção se caracteriza pela suspensão da eficácia das normas constitucionais, sem, contudo revogá-las e o homem medieval não conhecia tal forma de suspensão das normas; b) Para o mundo medieval, a exceção estava mais para um mecanismo de dispensa de obrigatoriedade da lei e, portanto, aplicado pontualmente. $O$ estado de exceção moderno já não é algo que possa ser pontual, pois todo o funcionamento do ordenamento jurídico reside, em última instância, na exceção soberana; c) o estado de exceção moderno se caracteriza pela criação de uma zona de indiscernibilidade em que fato e direito se coincidem. A exceção medieval não criava este espaço, mas simplesmente abria o sistema jurídico para a transgressão fática, promovendo uma flexibilização pontual da norma. 
revela a própria aporia: "a necessidade está dentro e fora da lei" (SAINTBONNET, 2001, p. 135) $)^{5}$.

Essa aporia quanto ao lócus da necessidade - o estar dentro e fora da ordem jurídica -, analogamente, manifesta a própria dificuldade da tradição jurídica em relação à estrutura topológica do estado de exceção moderno. Há aqueles que restringem os casos de necessidade às situações previstas no ordenamento jurídico e, para estes, o estado de exceção seria um direito, ius. Por outro lado, há aqueles que afirmam a completa impossibilidade de se positivar os casos de necessidade e, por conseguinte, consideram o estado de exceção um fenômeno eminentemente político, isto é, extrajurídico, exterior ao ordenamento, jurídico. Para esta última vertente teórica, o estado de exceção seria um fato, factum (AGAMBEN, 2007, p. 38). Ao se considerar a necessidade e, consequentemente, o estado de exceção, um simples fato ou um direito, depara-se com a seguinte aporia:

Se a medida de necessidade já é norma jurídica e não um simples fato, por que ela deve ser ratificada e aprovada por meio de uma lei, como Santi Romano (e a maioria dos autores como ele) considera indispensável? Se já era direito, por que se torna caduca se não for aprovada pelos órgãos legislativos? E se, ao contrário, não era direito mas simples fato, como é possível que os efeitos jurídicos da ratificação decorram não do momento da transformação em lei e, sim, ex tunc? [...]. Mas a aporia máxima, contra qual fracassa, em última instância, toda teoria do estado de necessidade, diz respeito à própria natureza da necessidade, que os autores continuam, mais ou menos inconscientemente, a pensar como uma situação objetiva." (AGAMBEN, 2007, p. 46).

O problema não passou despercebido pelos teóricos. Friedrich (1946, p. 238-239), por exemplo, afirma que, com a crescente complexidade da sociedade modelada por um número crescente de leis

5 No original: "la nécessité est soit dans soit hors l'ordre juridique". 
não menos complexas, as situações extraordinárias e urgentes acabam por trazer consigo, também, a urgência de poderes extraordinários para se realizarem mudanças legislativas imediatas. Como geralmente as Constituições calam sobre esse ponto e as situações extraordinárias surgem por força imperiosa da necessidade, poderes legislativos extraordinários seriam factíveis de concentração no Executivo, por concessão do Parlamento ou por usurpação. Nesse ponto, Friedrich cita o exemplo de Lincoln, que, diante das hostilidades, "sem um exército adequado e sem um Congresso disposto a autorizar sua criação, adotou medidas ilegais para alcançar este propósito aparentemente necessário" (FRIEDRICH, 1946, p. 238) ${ }^{6}$. E continua narrando que, posteriormente, "o Congresso legalizou o que havia feito o presidente [...]" (FRIEDRICH, 1946, p. 238-239) ${ }^{7}$. Dessa situação, Friedrich (1946) traz uma intuição aguçada sobre a aporia na qual está imersa a relação entre necessidade e constitucionalismo, afirmando que enquanto tais atos se realizarem com o manifesto propósito de "manter o constitucionalismo, esse método funciona; todavia, está sujeito à objeção de que todas as infrações jurídicas são destrutivas dessa crença no direito na qual se baseia o constitucionalismo." (FRIEDRICH, 1946, p.238)

Ao se considerar, portanto, o estado de necessidade e o estado de exceção como fatos objetivos ou, por outro lado, como direitos positivados no ordenamento jurídico, não se consegue esclarecer a estrutura única do estado de exceção. Na verdade, a necessidade implica um juízo subjetivo e está longe de se resolver através de critérios meramente objetivos: o recurso da necessidade implica em uma valoração "moral e política (e, portanto, extrajurídica), pelo qual se julga a ordem jurídica e o que é

6 No original: "[...] sin un ejército adecuado y sin un Congreso dispuesto a autorizar su creación, adoptó medidas ilegales para conseguir este propósito aparentemente necesario."

7 No original: "Posteriormente el Congreso legalizó lo que había hecho el Presidente, aprobando una ley de indemnidad."

8 No original: "Mientras tales actos se realicen con el manifiesto propósito de mantener el constitucionalismo tal como lo interpreta la mayoría, este método 'funciona'; sin embargo, está sujeto a la objeción de que todas las infracciones jurídicas son destructivas de esa creencia en el derecho en la que se basa el constitucionalismo.". 
considerado digno de conservação ou de aprimoramento, ainda que sob o preço de sua violação temporária" (PALLIERI, 1950, p. 141)9.

As circunstâncias normais se tornam excepcionais ou necessárias exclusivamente através uma decisão que assim as qualifiquem. Tanto a necessidade como a exceção se reduzem, em última instância, a uma decisão. Falhada a tentativa de ancorar o estado de exceção ao estado de necessidade, se aquele não é direito (ius) e tampouco um simples fato (factum), caberia, portanto, perguntar qual é a tônica desta singularidade.

\section{A decisão e o estado de exceção}

O estado de exceção, como fenômeno singular, é marcado pela confluência de duas ideias: a desnecessidade de uma situação de perigo efetivo ou fático para declará-lo e a suspensão das normas constitucionais protetoras da liberdade individual. Ambas as ideias são frutos da tradição democrático-revolucionária, porquanto surgiram no período histórico da revolução francesa.

O estado de sítio (état de siège effectif, réel ou militaire), originalmente, foi uma instituição militar atrelada a algumas situações de ataque efetivo ou real contra as fortificações permanentes. A declaração do estado de sítio estava condicionada às situações fáticas militares reais, denotando claramente a relação entre aquele e o plano fático (REINACH, 1885, p. 92-93; SCHMITT, 2009, p. 236). O estado de sítio real, portanto, não surgia em virtude de uma simples decisão do Executivo ou deliberação do Legislativo, ou melhor, não poderia ser criado do nada (ex nihilo), por lei ou por decreto.

Entretanto, essa origem tradicional foi alterada por Napoleão, através do decreto de 24 de dezembro de 1811, ampliando o conteúdo

\footnotetext{
9 No original: "[...] il ricorso alla necessità implica una valutazione morale o politica (e comunque extra-giuridica) per la quale si giudica l'ordine giuridico, e lo si ritiene degno di conservazione o di potenziamento anche a prezzo di una sua temporanea violazione."
} 
do estado de sítio. Napoleão, às vésperas da campanha contra a Rússia, teve receio de eventuais tumultos da população contra as cidadelas às margens do Rio Reno. Com o objetivo de preservar as fortificações, estabeleceu que o estado de sítio poderia ser determinado simplesmente por um decreto do imperador, considerando, portanto, não apenas o inimigo externo, mas também o inimigo interno (REINACH, 1889, p. 9899; SCHMITT, 2009, p. 236-241).

Soltando as amarras fáticas às quais o estado de sítio estava condicionado, Napoleão lançou as bases para a utilização política dessa instituição. Em contraposição ao estado de sítio real (militar, efetivo ou fático), surgia, por conseguinte, o estado de sítio político ou fictício (état de siège fictif), permitindo a implantação dessa exceção caso se considerasse necessário, segundo as conveniências políticas, independentemente das situações fáticas reais (SCHMITT, 2009, p. 240).

Ao lado dessa utilização política do estado de sítio, encontrase a ideia de suspensão das normas constitucionais protetoras da liberdade individual. O artigo 92 da Constituição de frimário do ano VIII declarava explicitamente a possibilidade de suspensão das normas constitucionais em casos de agitações ou revoltas armadas que ameaçassem a segurança interna do Estado, desde que a suspensão fosse determinada por lei. O Poder Executivo poderia determinar a suspensão da constituição através de decreto apenas quando o corpo legislativo não estivesse reunido (REINACH, 1885, p. 96). Todavia, o artigo 92 da Constituição de 22 de frimário do ano VIII, apesar de indicar a possibilidade de suspender o "império da constituição", não fez menção ao estado de sítio, real ou fictício. Não se havia, ainda, estabelecido o nexo entre estado de sítio e suspensão das normas constitucionais (SCHMITT, 2009, p. 240).

Da convergência dessas duas ideias revolucionárias surgiria o fenômeno único do estado de exceção, porquanto este, a exemplo do état de siège fictif, não necessita da existência de uma situação de ataque real para ser declarado. Em última instância, as situações fáticas reais tornam-se desnecessárias para a declaração do estado de sítio 
político ou do estado de exceção, convergindo, ambos os fenômenos, no ponto da decisão. Por outro lado, se o que é incito ao estado de exceção é a suspensão, total ou parcial, do ordenamento jurídico (AGAMBEN, 2007, p. 39), aquele se estrutura à semelhança do modelo de suspensão das normas constitucionais, introduzido pelo artigo 92 da Constituição de 22 de frimário do ano VIII.

A decisão soberana haveria de cristalizar, em um único ponto, essas duas ideias, pois, ao mesmo tempo em que suspende as normas constitucionais, demonstra não apenas a completa desnecessidade das situações fáticas reais para se constituir o estado de exceção, mas também a inteira independência em relação à normatividade jurídica. $O$ que o estado de exceção propõe, à semelhança do milagre, é a interrupção da continuidade jurídica, a suspensão do ordenamento jurídico, no todo ou em parte, necessária para que seja possível criar a situação de normalidade imprescindível para a aplicação da própria normatividade jurídica. O contínuo funcionamento normal do ordenamento jurídico mecanismo entorpecido pela burocratização impessoal e pela repetição engendrada pelo modelo de norma jurídica universalmente válida para todas as situações - é interrompido pela irrupção da vida, pela situação de exceção.

O estado de exceção, como delineado em Teologia Política (Politische Theologie), por conseguinte, não se confunde integralmente com o estado de sítio, ou mesmo com as denominadas ditadura comissária e ditadura soberana.

Schmitt havia tratado da exceção e da soberania em A Ditadura (Die Diktatur). A ditadura comissária, clássica, cujas raízes históricas Schmitt (2009, p. 33-34) busca no direito romano, diante de situações concretas ameaçadoras da ordem constitucional, teria como função suspender a Constituição por um determinado tempo, com o objetivo de protegê-la. Todavia, as normas constitucionais continuariam válidas, porquanto a suspensão seria apenas uma exceção concreta e temporal (SCHMITT, 2009, p.181-182). Por outro lado, a ditadura soberana, revolucionária, com origem na Revolução Francesa, não suspenderia a 
Constituição vigente com fins de protegê-la; ao contrário, eliminá-la-ia, com vistas a criar uma nova Constituição (SCHMITT, 2009, p.182-183).

A posição estratégica da ditadura comissária, em Schmitt, seria evitar mudanças na ordem política oriundas de eventuais tentativas de instauração da ditadura soberana. Ao contrapor a ditadura comissária à ditadura soberana, revela-se o significado da exceção para o Schmitt de A Ditadura: a exceção não seria um milagre, mas uma patologia (MCCORMICK, 1999, p. 136). A situação de exceção - e Schmitt já afirmava a impossibilidade de codificação de todas as situações excepcionais - se revela no perigo do aparecimento de traços fáticos de uma ditadura soberana, exigindo, portanto, a instauração de uma ditadura comissária a fim de expurgar a situação de anormalidade.

Contudo, em Teologia Política, Schmitt (2004, p. 13) faz uma verdadeira apologia da exceção, ligando-a diretamente à figura do soberano, afirmando que este é quem decide sobre a exceção. Proclama, ainda, categoricamente, que a exceção é mais interessante do que a norma. Para Schmitt, a exceção confirma não apenas a norma, mas a própria existência (SCHMITT, 2004, p. 20-21).

O relevante para este artigo não é buscar os motivos pelos quais Schmitt tenha, possivelmente, alterado a própria posição teórica, mas apenas pontuar como o estado (situação, Der Zustand) de exceção, elaborado em Teologia Política, distancia-se teoricamente das ditaduras comissária e soberana. Schmitt (2009, p. 184) afirma que o milagre político não se encontraria na ditadura emergente em si, mas na suspensão das leis, efetivando, assim, a ruptura da continuidade jurídica. As ditaduras comissária e soberana não estão aptas a realizar tal interrupção, pois elas têm um compromisso com a continuidade jurídica (SCHMITT, 2009, p. 185).

O elemento comum entre ditadura comissária e estado de exceção é a suspensão da norma, mas enquanto naquela a suspensão é limitada temporalmente, neste não há tal restrição. Tanto um como outro, em que pesem as diferenças, demonstram a separação entre norma de direito e norma de realização do direito, ou seja, a absoluta independência entre a norma e a aplicação. Por outro lado, o estado de exceção não se confunde 
com a ditadura soberana, pois esta não suspende o ordenamento, mas o aniquila, a fim de criar uma nova Constituição.

A concisa e famosa formulação de Schmitt (2004, p. 13), segundo a qual "soberano é quem decide sobre o estado de exceção"10, demonstra a genuinidade da decisão, pois cabe a esta suspender a norma, abrindo o campo para que o soberano possa dispor sobre as relações normais da vida (normalizar, esquadrinhar a vida) e a norma voltar a ser aplicada comumente. Na exceção, o poder da vida real rompe a crosta do mecanismo que se tornou entorpecido pela repetição (SCHMITT, 2004, p. 21).

Dentro desse contexto, a decisão soberana revela uma fratura insuperável: a completa independência da norma (SCHMITT, 2004, p. 19). A decisão suspenderia o ordenamento jurídico e, ao mesmo tempo, possibilitaria estabelecer a situação de normalidade fática pressuposta para que as próprias normas jurídicas fossem aplicadas. Quando Schmitt afirma que soberano é quem decide sobre (über) a exceção, há um duplo sentido construtivo na palavra über. As situações excepcionais não podem ser codificadas completamente e, por isso, a decisão sobre a exceção tem a vitalidade de constituí-las. Por outro lado, decidir sobre a exceção implica, também, escolher as atitudes concretas a serem tomadas diante da anormalidade, ou melhor, o soberano deve decidir sobre o que deve ser feito para se criar a situação de normalidade novamente. O que se torna visível nessa estrutura de exceção, portanto, é a oposição entre norma e aplicação, e, ao mesmo tempo, entre norma e decisão (AGAMBEN, 2004, p. 58).

Em suma, a decisão suspende o ordenamento jurídico e constitui uma situação (Der Zustand) de exceção, uma zona cinzenta diante da qual o soberano deve estabelecer as condições de normalidade factual, com o objetivo de tornar possível a aplicação do direito. O estado de exceção "introduz no direito uma zona de anomia para tornar possível a normatização efetiva do real" (AGAMBEN, 2004, p. 58).

10 No original: "Souverän ist, wer über den Ausnahmezustand entscheidet". 
Aaporia do lócus da necessidade, aquela que corresponde também ao da exceção - o estar dentro e fora da ordem jurídica -, Schmitt pôde resolver justamente com a figura do soberano, pois este, ao estar dentro e fora da ordem jurídica, é quem garantiria a ancoragem do estado de exceção ao ordenamento jurídico. Se o soberano se circunscrevesse completamente à ordem jurídica, a decisão estaria restringida à norma jurídica, impossibilitada de versar sobre a exceção, de constituí-la. Portanto, apesar de fazer parte do ordenamento jurídico e, assim, garantir a ancoragem jurídica do estado de exceção, o soberano deve, por outro lado, estar fora, libertando-se das amarras advindas do direito, para que, decidindo sobre (über) a exceção, realize o milagre assegurador das relações normais da vida. Uma vez que a normatividade jurídica se encontra suspensa em virtude da decisão soberana, o soberano, por também deve se encontrar dentro do ordenamento jurídico, garante o respaldo jurídico da situação excepcional.

Articulando entre ordenamento jurídico e anormalidade, pode o soberano, através do estado de exceção, introduzir "uma zona de anomia para tornar possível a normatização efetiva do real" (AGAMBEN, 2004, p. 58) e salvar o próprio direito, nem que para isso precise suspender o ordenamento jurídico. Em última instância, o próprio ordenamento jurídico funciona ancorado ao estado de exceção, ou melhor, vive da exceção.

Se no estado de exceção a "norma se aplica à exceção desaplicando-se” (AGAMBEN, 2010, p. 24), isto é, se a situação excepcional surge como resultante da suspensão do ordenamento jurídico, caberia perguntar o que acontece com o direito, notadamente os direitos fundamentais, nessa zona cinzenta na qual fato (factum) e direito (ius) se tornam indiscerníveis, em que vida e norma se mesclam em uma completa indeterminação.

\section{0 estado de exceção como um vazio de direito}

Teorizando sobre o mecanismo da exceção, pelo qual o direito é suspenso e o fato é eliminado, produzindo "um patamar de 
indiscernibilidade em que factum e ius se atenuam um ao outro" (AGAMBEN, 2007, p. 46), Agamben descreve as principais características do direito no estado de exceção.

Uma delas é a inobservância, ou melhor, a impossibilidade de distinção entre observância e transgressão do direito. Se o direito se encontra em sua forma de suspensão, implicando a coincidência com a realidade, torna-se impossível observar a lei. Um comportamento que aparentemente segue a lei pode, ao contrário, significar uma transgressão e vice-versa (AGAMBEN, 2005, p. 105).

Como corolário da inobservância, há a informulabilidade do direito. Se for impossível observar a lei no estado de exceção, o direito não pode ter a forma de prescrição ou proibição. Essa impossibilidade de se formular significa que no estado de exceção o direito não figura como um novo corpo de normas proibitivas ou permissivas, pois o que existe é tão somente a suspensão do ordenamento jurídico, tornando, portanto, impossível discernir entre lícito e ilícito (AGAMBEN, 2005, p. 105-106).

Agamben exemplifica essa característica da informulabilidade através do Decreto do Presidente do Reich para a proteção do Povo e do Estado, de 28 de fevereiro de 1933. Esse decreto suspendia os artigos 114, 115, 117, 118, 123, 124 e 153 da Constituição de Weimar, todos eles relacionados à liberdade individual, restringindo, por exemplo, direitos de liberdade de expressão e imprensa, de reunião e associação, ao sigilo postal e das comunicações telegráficas, à propriedade e à inviolabilidade do domicílio (ALEMANHA, 1933) ${ }^{11}$. Com a simples

11 "Decree of the Reich President for the Protection of the People and State of 28. February 1933. On the basis of Article 48, Section 2, of the German Constitution, the following is decreed as a defensive measure against Communist acts of violence that endanger the state: $\S 1$ Articles 114, $115,117,118,123,124$, and 153 of the Constitution of the German Reich are suspended until further notice. Thus, restrictions on personal liberty, on the right of free expression of opinion, including freedom of the press, on the right of assembly and the right of association, and violations of the privacy of postal, telegraphic, and telephonic communications, and warrants for house searches, orders for confiscations as well as restrictions on property are permissible beyond the legal limits otherwise prescribed". 
suspensão dos artigos da Constituição, torna-se impossível saber previamente o que é lícito e ilícito (AGAMBEN, 2005, p. 106).

A principal feição do direito no estado de exceção, por fim, encontra-se na indeterminação absoluta entre fora e dentro, entre anomia e nómos, entre vida e norma, entre factum e ius (AGAMBEN, 2005, p.105). O "estar-fora e, ao mesmo tempo, pertencer" (AGAMBEN, 2007, p. 57) indica o paradoxo implícito na própria suspensão do ordenamento jurídico. Esse limiar de indeterminação entre ius e factum, entre nómos e anomia, entre direito e vida, é o lócus sobre o qual recai incessantemente a decisão. A articulação entre o que está dentro do ordenamento (o elementos jurídico, nómos) e o que está fora dele (o elemento metajurídico, anomia) somente é possível por causa do estado de exceção, pois a suspensão (total ou parcial) do ordenamento jurídico perpetra uma zona ambígua e incerta em que os "procedimentos de fato, em si extra ou antijurídicos, transformam-se em direito e na qual as normas jurídicas se indeterminam em mero fato" (AGAMBEN, 2007, p.45).

Primo Levi (1998, p. 81) relata em É isto um homem? que no campo de concentração existiam dois tipos de contrabando. Uma das espécies consistia na troca de produtos do campo entre os prisioneiros e os trabalhadores externos, os operários civis, e essa troca era severamente punida e reprimida pela direção do campo (LEVI, 1998, p. 83-84). Todavia, havia outra forma, que consistia na receptação de produtos da fábrica externa, e esse escambo era tolerado pela direção. Todavia, como a fábrica estava fora, sob a responsabilidade das autoridades civis, o roubo desses produtos para que fossem trocados com os prisioneiros era passível de punição por essas autoridades. Levi traz a seguinte reflexão: "Desejaríamos, agora, convidar o leitor a meditar sobre o significado que podiam ter para nós, dentro do Campo, as velhas palavras 'bem' e 'mal', 'certo' e 'errado'." (LEVI, 1998, p. 87).

Em abril de 1961, no julgamento em Jerusalém, Eichmann repetira várias vezes que "[...] as palavras do Führer tinham força de lei [...]" (ARENDT, 1983, p. 160). Isso pode levar à interpretação segundo 
a qual, no estado de exceção, produzia-se uma confusão entre os poderes executivo e legislativo, mas se a situação excepcional instaura um limiar de indeterminação entre ius e factum, nómos e anomia, direito e vida, norma jurídica e violência, o que existe não é tanto um espaço de plenitude de poderes jurídicos, e sim um kenomatico, um vazio jurídico. O que está em jogo, portanto, no estado de exceção, é uma força-de-lei sem lei, enunciada no sintagma força-de-łei, com um tachado na palavra "lei", demonstrando que, apesar da suspensão da norma, a força desta persiste. A eficácia da lei não se confunde com a força do ato:

A eficácia consiste na produção dos efeitos, da consequência jurídica, e tal produção não se identifica mais com a força do ato, pois a força do ato, ao invés disso, diz respeito ao momento em que se deve determinar se $o$ ato é ou não é válido, em comparação com outros que possam eventualmente se sobreporem a ele. Diferentemente da eficácia, força exprime, portanto, um critério relacional entre os atos do poder público e diz respeito à escolha daquele que, entre os diversos atos mais conflitantes, deve ser considerado como eficaz, como operante na esfera social. A ideia de force of Law, de force juridique, refere-se a qualquer ato normativo, independentemente da apreciação da relação em que tal ato se encontre com os outros e do pressuposto de que a escolha já fora feita entre vários atos conflitantes; isto é, a identificação da força do ato normativo com a sua autoridade contra os cidadãos, com a sua capacidade de dirigir a conduta dos destinatários da norma, em outras palavras, com a sua obrigatoriedade, expressa, na realidade, apenas a superioridade, a supremacia do Estado e do ordenamento jurídico em relação aos sujeitos, e caracteriza cada ato normativo válido: se trata, portanto, na realidade, da eficácia do ato, de sua capacidade de produzir efeitos jurídicos em confronto com seus destinatários. Essa idéia também conduz, inevitavelmente, à atribuição de força de lei a todos os atos normativos, mesmo àqueles que estão 
em um nível mais baixo na hierarquia das fontes. (QUADRI, 1997, p.10) $)^{12}$.

To enforce the law significa mais do que aplicar o direito e não encontra uma tradução exata no idioma português. Enforcement implica força, ou melhor, fazer algo acontecer por meio da força, portanto, to enforce the law implica uma força autorizada (DERRIDA, 2010, p. 7-8). Entretanto, justamente no contexto do estado de exceção, a força-delei se transmuta em força-de-łed, uma "fictio pela qual o direito busca se atribuir sua própria anomia” (AGAMBEN, 2004, p. 61).

O mecanismo de suspensão da norma permite justamente a captura de um espaço de anomia. Se a norma se aplica ao caso excepcional desaplicando-se (suspendendo-se) e, consequentemente, criando um espaço em que fato e norma se tornam indiscerníveis, a violência e o direito também se encontram indiscerníveis nesse limiar. Entretanto, apesar de haver toda essa indistinção, o soberano deve decidir o que é violência e o que é direito, sobre o valor e o desvalor da vida. Ao se proceder à suspensão provisória da norma e à conseguinte criação da esfera de sua aplicação, o estado de exceção está criando um espaço onde atua o império da força-de-łei, que nada mais é do que uma violência travestida de força jurídica. Mais uma vez, é Primo Levi (2004, p. 79-80) quem relata a experiência dos prisioneiros no campo

12 No original: "L'efficacia consiste nella produzione degli effetti, delle conseguenze giuridiche, e tale produzione non se identifica mai con la forza dell'atto poiché la forza dell'atto riguarda invece il momento in cui si deve stabilire se l'atto sia o meno valido, rispetto ad altri che possano eventualmente sovrapporsi ad esso. A differenza dell'efficacia, la forza esprime dunque un criterio relazionale fra gli atti del pubblico potere e riguarda la scelta di quello che, fra più atti confliggenti, dovrà considerarsi come efficace, come operativo nell'ambito sociale. L'idea della force of Law, della force juridique riferita ad ogni atto normativo, indipendentemente dalla considerazione del rapporto in cui tale atto viene a trovarsi con altri atti e sul presupposto che una scelta sia stata già operata fra più atti confliggenti, l'identificazione cioè della forza dell'atto normativo con la sua autorità nei confronti dei consociati, con la sua capacità di indirizzare le condotte dei destinatari delle norma, in altri termini con la sua obbligatorietà, esprime in realtà unicamente la superiorità, la supremazia dello Stato e dell'ordinamento giuridico rispetto ai sudditi, e caratterizza ogni atto giuridico normativo valido: si tratta dunque, in realtà, dell'efficacia giuridica dell'atto, della sua attitudine a produrre effetti giuridici nei confronti dei suoi destinatari. Tale idea porta inoltre, irrimediabilmente, ad attribuire forza di legge a tutti gli atti normativi, anche quelli che si trovano al livello più basso nel sistema gerarchico delle fonti". 
de concentração em Auschwitz, narrando que, na dinâmica cotidiana do campo, a lei tornou-se totalmente indecifrável, ou seja, tudo se passava em uma zona cinzenta na qual o menor e mais comum dos atos poderia gerar consequências fatais. Uma zona cinzenta em que a ordem proferida no idioma alemão, se não compreendida por qualquer prisioneiro - italianos, espanhóis, franceses... - ou mesmo a hesitação no cumprimento, acarretava golpes. A lei somente era conhecida pelos prisioneiros no ato, na concretude da punição.

Se o estado de exceção está mais para um espaço kenomatico, um vacuum jurídico, do que para um pleromatico, uma plenitude de poderes jurídicos, a força-de-lei, portanto, no estado de exceção, não significa tanto a confusão entre os poderes, na qual decretos, medidas e disposições legais adquirem força, apesar de não oriundas do legislativo. Em última instância, o que está em jogo no estado de exceção é justamente um espaço vazio de direito, a anomia.

Hannah Arendt percebeu o princípio fundamental que regia os regimes totalitários e que viera à luz nos campos de concentração: o "tudo é possível" (ARENDT, 2009, p. 448; AGAMBEN, 2010, p. 166). Se no campo de concentração "tudo é possível" - e o que "o bom senso e as 'pessoas normais' se recusam a crer é que tudo seja possível" (ARENDT, 2009, p.491) - é porque esse espaço de exceção se mostrou um "híbrido de direito e de fato, no qual os dois termos tornam-se indiscerníveis" (AGAMBEN, 2010, p. 166), no qual todo conceito de direitos fundamentais, proteção jurídica e direito subjetivo perdera qualquer sentido.

A situação-limite dos campos, a materialização do estado de exceção, demonstrou que quando ius e factum, nómos e anomia, direito e vida, norma jurídica e violência se mesclam em uma zona cinzenta, na qual recai, incessantemente, uma decisão, esta poderá decidir sobre o valor e o desvalor da vida, sem, contudo, violar o direito. Entender essa estrutura do estado de exceção, em que a pessoa é desnudada da roupagem jurídico-política de cidadão pela violência estatal, tornase essencial, nem tanto para se perguntar se determinado regime é ou 
não totalitário, mas para descobrir os espaços e as medidas de exceção dentro das democracias.

Será um campo tanto os estádios de Bari, onde em 1991 a polícia italiana aglomerou provisoriamente os imigrantes clandestinos albaneses antes de reexpedi-los ao seu país, quanto o velódromo de inverno no qual as autoridades de Vichy recolheram os hebreus antes de entregá-los aos alemães; tanto o Konzentrationslager für Ausländer em Cottbus-Sielow, no qual o governo de Weimer recolheu os refugiados hebreus orientais, quanto as zones d'attente nos aeroportos internacionais franceses, nas quais são retidos os estrangeiros que pedem o reconhecimento do estatuto de refugiado. Em todos estes casos, um local aparentemente anódino (como, por exemplo, o Hotel Árcades, em Roissy) delimita na realidade um espaço no qual o ordenamento normal é de fato suspenso, e que aí se cometam ou não atrocidades não depende do direito, mas somente da civilidade e do senso ético da polícia que age provisoriamente como soberana [...]. (AGAMBEN, 2010, p. 170).

Nas teses sobre o conceito de história (Über den Begriff der Geschichte), Walter Benjamin (2007, p. 133) havia dito que a "tradição dos oprimidos nos ensina que o 'estado de exceção', em que vivemos, é a regra"13. Longe de se constituir em uma quimera, a afirmativa de Benjamin se faz atual, notadamente quando medidas excepcionais surgem como práticas gerenciais de governo, buscando administrar o curso das coisas, "adaptando-se a cada vez, em seu intento salvífico, à natureza da situação concreta com que deve medir forças" (AGAMBEN, 2011, p. 64).

A ideia segundo a qual a teoria do estado de exceção não pode ser um fim em si mesmo, "senão que tem que estar inscrita em um conjunto mais amplo, no contexto das tecnologias de governo"

13 No original: "Die Tradition der Unterdrückten belehrt uns darüber, daß der ,Ausnahmezustand', in dem wir leben, die Regel ist". 
(AGAMBEN, 2014, p. 25), deve nortear o olhar. O vocábulo alemão Ausnahmezustand, algumas vezes traduzido como estado de exceção, indica, na verdade, uma situação (Zustand) emergencial, excepcional. Em Ausnahmezustand, Zustand (estado) não se identifica com Staat (estado), como presente, por exemplo, na expressão estado de direito (Rechtsstaat). Seria tão ou mais proveitoso, por conseguinte, inquirir não se um governo é ou não democrático, mas sim os espaços e as medidas de exceção existentes dentro das democracias. Será um espaço de exceção, portanto, tanto o campo de concentração quanto as áreas de segurança no entorno dos estádios de futebol estabelecidas durante a Copa do Mundo FIFA 2014, nas quais o direito fundamental de ir e vir estava suspenso, porquanto o cidadão comum não poderia penetrar nestas "áreas de segurança", "e que aí se cometam ou não atrocidades não depende do direito, mas somente da civilidade e do senso ético da polícia que age provisoriamente como soberana" (AGAMBEN, 2010, p. 170). Serão medidas de exceção tanto as técnicas antropométricas e a identificação datiloscópica, originalmente utilizadas para identificar criminosos, quanto a identificação biométrica imposta aos cidadãos brasileiros através do recadastramento biométrico eleitoral, implicando o pressuposto de que todos são potencialmente perigosos.

$\mathrm{Se}$, dentro das democracias, medidas excepcionais encontram-se como prática de governo, isso deve levar à reflexão de que o estado de exceção feito regra tornou-se o "nómos do moderno" (AGAMBEN, 2010, p. 162), trazendo à luz a matriz oculta da política da modernidade. Quando o estado de exceção tende a se tornar a regra, a política vive da permanente indistinção entre fato e norma jurídica, através de medidas excepcionais e zonas cinzentas nas quais as vidas das pessoas tornamse visivelmente abandonadas ao extremo.

\section{Conclusão}

A ideia do estado de necessidade não resolve adequadamente o problema da suposta ancoragem legal do estado de exceção; apenas reforça a aporia na qual se encontra. Instituído em virtude de uma decisão 
soberana, o estado de exceção, na verdade, é um espaço kenomatico, um vazio jurídico, e nem tanto um pleromatico, plenitude de poderes jurídicos, porquanto a suspensão, total ou parcial, do ordenamento jurídico produz uma zona em que fato e direito se tornam indiscerníveis. Se, por um lado, a suspensão da norma traz consigo a inobservância do direito, a impossibilidade de se distinguir entre observância e transgressão do direito, por outro, o mecanismo de suspensão da norma também acarreta na informulabilidade do direito, isto é, este, no estado de exceção, não pode ser formulado como prescrição ou proibição. Por último, talvez como principal característica do direito no estado de exceção, há a indeterminação absoluta entre fora e dentro, entre anomia e nómos, entre vida e norma, entre factum e ius, revelando o lócus ímpar do fenômeno.

Justamente nesse cenário, a força-de-lei se transmuta em forçade-lei, pois, apesar da suspensão da norma, a força desta persiste. Quando ius e factum, nómos e anomia, direito e vida, norma jurídica e violência se indeterminam, abre-se a possibilidade da incidência da decisão. A monstruosa ironia reside justamente na constatação de que cabe à decisão, através de um veredicto performativo, instituir o espaço de exceção (campo de indeterminação) e, ao mesmo tempo, ditar a determinação. Cabe à decisão a tarefa de suspensão da norma e, consequentemente, decidir sobre o que é direito e o que é violência, entre ius e factum, nómos e anomia, podendo, portanto, decidir também sobre o valor e o desvalor da vida, sem violar o direito. Quando o estado de exceção foi realizado de forma permanente, na forma do campo de concentração, espaço no qual os conceitos de proteção jurídica e direitos subjetivos perderam todo sentido, demonstrou-se, afinal, como a pessoa pode ser desnudada da roupagem jurídico-política de cidadão pela própria política que Ihes atribuiu esse qualificativo.

$\mathrm{Na}$ política moderna, em que medidas excepcionais tornamse práticas corriqueiras de governo, entender a estrutura do estado de exceção mostra-se fundamental, nem tanto para se perguntar se determinado regime é ou não democrático, mas para descobrir os espaços e as medidas de exceção dentro das democracias. Se isso for 
verdade, caberia perguntar, agora, sobre o próprio papel do direito como solubilidade última dos problemas humanos, pois se o ordenamento jurídico, em última instância, funciona ancorado ao estado de exceção, ou melhor, vive da exceção, o instante supremo almejado intimamente pelo direito, o momento que reverbera e do qual necessita para viver, ironicamente, não seria o da paz, mas o da violência.

\section{Referências}

AGAMBEN, Giorgio. Estado de exceção. Tradução Iraci D. Poleti. 2. ed. São Paulo: Boitempo, 2007.

AGAMBEN, Giorgio. Estado de exceção e genealogia do poder. Revista brasileira de estudos políticos, Belo Horizonte, v.108, p. 23-39, jan./jul. 2014. Disponível em: <http://dx.doi.org/10.9732/P.00347191.2014v108p21>. Acesso em: 17 ago.2014.

AGAMBEN, Giorgio. Homo sacer: o poder soberano e a vida nua I. 2. ed. Tradução Henrique Burigo. Belo Horizonte: UFMG, 2010.

AGAMBEN, Giorgio. O reino e a glória: uma genealogia teológica do governo e da economia. Tradução Selvino J. Assmann. São Paulo: Boitempo, 2011.

AGAMBEN, Giorgio. Signatura rerum: sul metodo. Torino: Bollati Boringhieri, 2008.

AGAMBEN, Giorgio. The time that remains: a commentary on the Letter to the Romans. Tradução Patrícia Dailey. Stanford: Meridian, 2005.

ALEMANHA. Decree of the Reich President for the Protection of the People and State of 28. February, 1933. Disponível em: <http:// germanhistorydocs.ghi-dc.org/sub_document.cfm?document_ id=2325 $>$. Acesso em: 17 ago.2014.

ARENDT, Hannah. Eichmann em Jerusalém: um relato sobre a banalidade do mal. Tradução Sonia Orieta Heinrich. São Paulo: Diagrama \& textos, 1983. 
ARENDT, Hannah. Origens do totalitarismo. Tradução Roberto Raposo. São Paulo: Companhia das Letras, 2009.

BENJAMIN, Walter. Über den Begriff der Geschichte. In: BENJAMIN, Walter. Erzählen: Schriften zur Theorie der Narration und zur literarischen Prosa. Frankfurt am Main: Suhrkamp, 2007

DERRIDA, Jacques. Força de lei. 2. ed. Tradução Leyla PerroneMoisés. São Paulo: Martins Fontes, 2010.

ESPOSITO, Roberto. Bios: biopolítica e filosofia. Tradução M. Freitas da Costa. Lisboa: Edições 70, 2010.

FONTANA, Alessandro. Du droit de résistence au devoir d'insurrection. In: ZANCARINI, Jean-Claude. Le droit de résistence: XII-XX siècle. Paris: ENS, 1999.p.15-34

FOUCAULT, Michel. Segurança, território, população: curso no Collège de France (1977-1978). Tradução Eduardo Brandão. São Paulo: Martins Fontes, 2008.

FRIEDRICH, Carl J. Teoría y realidad de la organización constitucional democrática. Trad. Vicente Herrero. México: Fondo de Cultura Económica, 1946.

LEVI, Primo. É isto um homem? Tradução Luigi Del Re. Rio de Janeiro: Rocco, 1988.

LEVI, Primo. Os afogados e os sobreviventes. Tradução Luiz Sérgio Henriques. 2. ed. São Paulo: Paz e Terra, 2004.

MCCORMICK, John P. Carl Schmitt's critique of liberalism: against politics as technology. Cambridge: Cambridge University, 1999.

PALLIERI, G. Balladore. Diritto costituzionale. 2. ed. Milano: Dott. A. Giuffré, 1950.

QUADRI, Giovanni. La forza di legge. Milão: Dott. A. Giuffrè,1992.

REINACH, Théodore. De l'état de siège: étude historique et juridique. Paris: F. Pichon, 1885. 
SAINT-BONNET, François. L'état d'exception. Paris: Universitaires de France, 2001.

SCHMITT, Carl. La dictadura. 3. ed. Trad. José Diaz Garcia. Madrid: Alianza, 2009.

SCHMITT, Carl. Politische theologie: Vier Kapitel zur Lehre von der Souveränität. 8. ed. Berlim: Duncker \& Humblot, 2004.

Recebido em: 26/08/2014 Aprovado em: 26/03/2015 